\title{
THE EVALUATION OF THERMAL STRESSES IN THERMOPLASTIC LAMINATED COMPOSITES WITH DIFFERENT SQUARE HOLES
}

\author{
Faruk Şen*, Mustafa Toparlı** and N. Sinan Köksal*** \\ "Dokuz Eylul University, Department of Mechanical Engineering, \\ Bornova, Izmir, Turkey. faruk.sen@deu.edu.tr \\ ** Dokuz Eylul University, Department of Metallurgical and \\ Materials Engineering, Tinaztepe, Izmir Turkey \\ ${ }^{* * *}$ Celal Bayar University, Department of Mechanical Engineering, \\ Muradiye, Manisa, Turkey
}

\begin{abstract}
In this study, a thermal stress analysis was evaluated on symmetric angle-ply laminated thermoplastic composite plates that were having different square hole dimensions. The temperature loading was selected uniformly. Besides, it was applied with various values that were chosen as $50,60,70,80,90,100^{\circ} \mathrm{C}$, because of the fact that the effect of increasing uniform temperature on thermal stresses was examined. The width plate-to-the width square hole, a/b, ratios were changed as 2 , and 4 . Thermoplastic laminated composite plates were assumed to be simple supported. Laminated plates were composed of four orthotropic layers oriented with angle-ply in symmetric manner. The solution was carried out by using ANSYS finite element program. The results were showed in figures depending on applied temperatures, orientations and dimensions of square hole.
\end{abstract}

Key words- Laminated composites, thermoplastic composites, thermal stress, ANSYS

\section{INTRODUCTION}

Availability of the new, low cost, high performance fiber reinforced plastic (FRP) structural composites for infrastructure construction and rehabilitation has given an impetus to the development of a new technology in construction industry. Inherent lightness, placement flexibility, corrosion resistance, high strength to weight ratio, low relaxation/creep, high fatigue resistance, and magnetic transparency of FRP composites make them attractive as logical substitutes for steel structural elements [1].

Wang et al. [2] offered an analytical method in order to determine the thermal residual stresses in an isotropic plate reinforced with a circular orthotropic patch. Gigliotti et al. [3], focused on the out-of-plane displacements, i.e., curvatures, induced by uniform thermal fields in 0/90 laminated square plates. Sayman and Kayrici [4] studied elastoplastic stress analysis on a thermoplastic composite cantilever beam subjected to a single transverse force applied to the free end of the beam. Senel et al. [5], were performed residual stress analysis of laminated composite plates under thermal loads and they used analytical methods.

Shabana and Noda [6] have investigated elasto-plastic thermal stresses in a rectangular plate of a particle reinforced composite functionally graded materials were treated by finite element method. In their analysis, the thermal stress constitutive equation of a particle-reinforced composite taking temperature change and damage process into consideration was used. Sayman et al. [7], a thermal elastic-plastic stress analysis was carried out on a steel fiber high-density polyethylene matrix composite beam. The 
distribution of residual stress and deformations in the beam were obtained for the case that the temperature distribution varies linearly between the upper and lower surfaces. Öndürücü and Topcu [8] studied an elastic-plastic stress analysis on simply supported thermoplastic composite laminated plates. The temperature was selected parabolically from $-\mathrm{T}_{0}$ to $\mathrm{T}_{0}$ through the thickness of the plates.

In the present study, a thermal stress analysis was performed on symmetric angle-ply laminated thermoplastic composite plates that were assumed having two different square hole dimensions. The finite element methods were used to calculate thermal stress distributions. The temperature loading was also selected uniformly.

\section{MATERIALS AND METHODS}

\subsection{Definition of the Problem}

A thermal stress analysis was carried out on thermoplastic laminated composite plates with various square holes. Mechanical properties of thermoplastic composite material were given in Table 1 [9].

Table 1. Mechanical properties of the thermoplastic composite material

\begin{tabular}{cccccc}
\hline $\begin{array}{c}\mathrm{E}_{1} \\
(\mathrm{MPa})\end{array}$ & $\begin{array}{c}\mathrm{E}_{2} \\
(\mathrm{MPa})\end{array}$ & $\begin{array}{c}\mathrm{G}_{12} \\
(\mathrm{MPa})\end{array}$ & $v_{12}$ & $\begin{array}{c}\alpha_{1} \\
\left(1 /{ }^{\circ} \mathrm{C}\right)\end{array}$ & $\begin{array}{c}\alpha_{2} \\
\left(1 /{ }^{\circ} \mathrm{C}\right)\end{array}$ \\
\hline 41000 & 1200 & 420 & 0.25 & $12.6 \times 10-6$ & $130.0 \times 10^{-6}$ \\
\hline
\end{tabular}

The thermoplastic laminated plate consists of high-density polyethylene as matrix material and it was reinforced steel fibers. The laminated plate was formed from four layers. The thickness of each layer was $2 \mathrm{~mm}$. The stacking sequence of laminated plates were selected symmetrically as $\left[15^{\circ} /-15^{\circ}\right]_{\mathrm{s}}, \quad\left[30^{\circ} /-30^{\circ}\right]_{\mathrm{s}}$ and $\left[60^{\circ} /-60^{\circ}\right]_{\mathrm{s}}$. Dimensions and symmetric stacking sequence of square composite layers with square hole were shown in Figure 1. The width of square laminated plate was assumed as 200 $\mathrm{mm}$, whereas the widths of square hole were selected as 100 and $50 \mathrm{~mm}$ for Model 1 and Model 2, respectively. In other words, the width square plate-to-the width square hole, $\mathrm{a} / \mathrm{b}$, ratios were changed as 2 , and 4 .

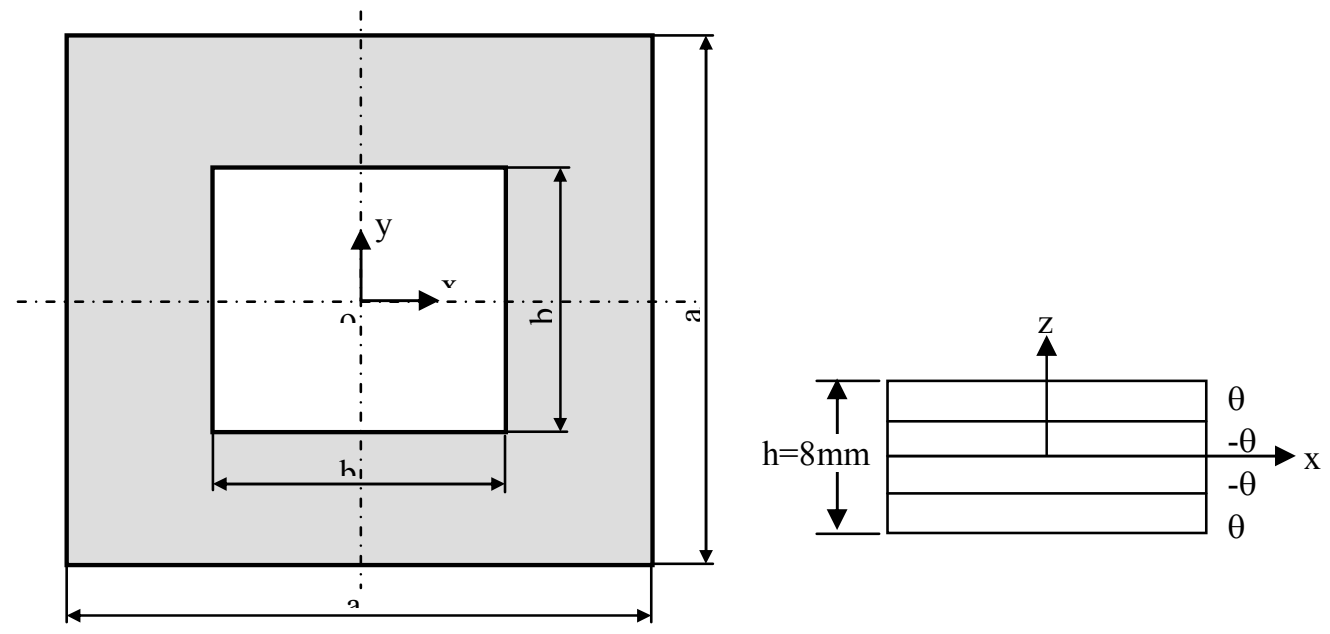

Figure 1. Dimensions and stacking sequence of the composite plate 
The distributions of thermal stress components were calculated by Finite Element Method (FEM) during the thermal stress analysis. For this purpose, the solution was carried out by using ANSYS finite element program, which is known advanced engineering simulation. Element type was also selected as SHELL99 for FEM solution. It was shown in Figure 2. The element type allows up to 250 layers. If more than 250 layers are required, a user-input constitutive matrix is available. The element has also six degrees of freedom at each node, translations in the nodal $\mathrm{x}, \mathrm{y}$, and $\mathrm{z}$ directions and rotations about the nodal $\mathrm{x}, \mathrm{y}$, and z-axes [10].

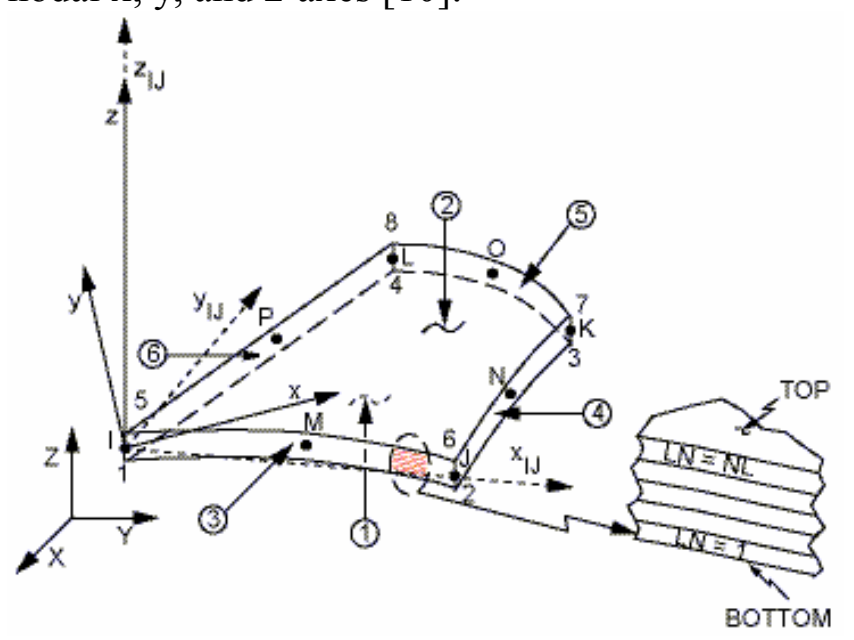

Figure 2. SHELL99 element type in ANSYS [10]

Finite element models and applied boundary conditions both Model 1 and Model 2 were shown in Figure 3.

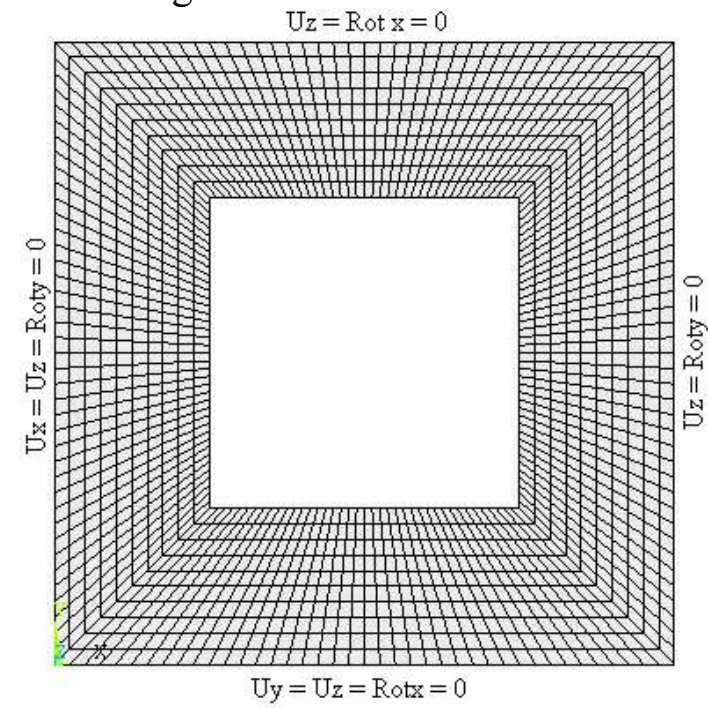

a) Model 1

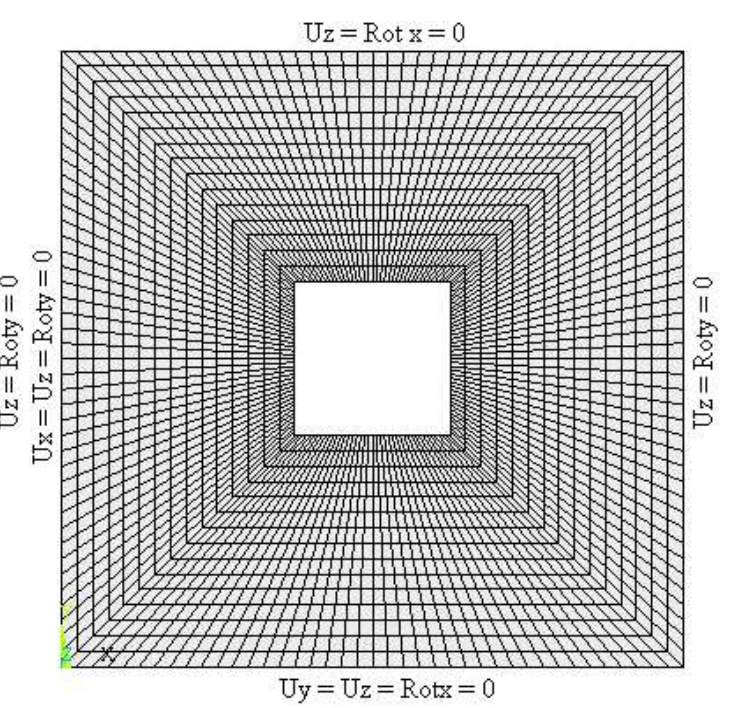

b) Model 2

Figure 3. Finite element models and boundary conditions with a square hole

It is seen that in this figure, laminated composite plates were assumed to be simple supported. Besides, the mapped mesh shape was also preferred for the period of the mesh process, since this mesh structure is firstly proposed if it is possible. After the 
mesh generation process, 1600 elements and 5120 nodes for Model 1 and 2400 elements and 7520 nodes for Model 2 were produced using ANSYS software.

\subsection{Mathematical Formulation}

The three-dimensional thermo elastic anisotropic strain-stress relations are given as [11],

$\varepsilon_{\mathrm{i}}=\mathrm{S}_{\mathrm{ij}} \sigma_{\mathrm{j}}+\alpha_{\mathrm{i}} \Delta \mathrm{T} \quad \mathrm{i}, \mathrm{j}=1,2, \ldots . ., 6$

where the total strains, $\varepsilon_{i}$, are the sum of the mechanical strains, $S_{i j} \sigma_{j}$, and the six free thermal strains, $\alpha_{\mathrm{i}} \Delta \mathrm{T}$, for a temperature change $\Delta \mathrm{T}$. The three-dimensional stressstrain relations are obtained by inversion:

$\sigma_{\mathrm{i}}=\mathrm{C}_{\mathrm{ij}}\left(\varepsilon_{\mathrm{i}}-\alpha_{\mathrm{j}} \Delta \mathrm{T}\right) \quad \mathrm{i}, \mathrm{j}=1,2, \ldots ., 6$

In both Equations (1) and (2), the six $\alpha_{i}$ are the coefficients of thermal deformation (expansion or contraction and distortion, i.e., shear), and $\Delta T$ is the temperature difference. In equation (2), if the total strain is zero the terms $C_{i j} \alpha_{j} \Delta T$ will be the thermal stresses [11],

For plane stress case on an orthotropic lamina in principal material coordinates, the principal stresses are written as,

$$
\left[\begin{array}{c}
\sigma_{1} \\
\sigma_{2} \\
\tau_{12}
\end{array}\right]=\left[\begin{array}{ccc}
Q_{11} & Q_{12} & 0 \\
Q_{12} & Q_{22} & 0 \\
0 & 0 & Q_{66}
\end{array}\right]\left[\begin{array}{c}
\varepsilon_{1}-\alpha_{1} \Delta T \\
\varepsilon_{2}-\alpha_{2} \Delta T \\
\gamma_{12}
\end{array}\right]
$$

The stresses in laminate coordinates for the $\mathrm{k}^{\text {th }}$ layer are obtained by transformation of coordinates.

$$
\left[\begin{array}{c}
\sigma_{x} \\
\sigma_{y} \\
\tau_{x y}
\end{array}\right]_{k}=\left[\begin{array}{lll}
\bar{Q}_{11} & \bar{Q}_{12} & \bar{Q}_{16} \\
\bar{Q}_{12} & \bar{Q}_{22} & \bar{Q}_{26} \\
\bar{Q}_{16} & \bar{Q}_{66}
\end{array}\right]\left[\begin{array}{c}
\varepsilon_{x}-\alpha_{x} \Delta T \\
\varepsilon_{y}-\alpha_{y} \Delta T \\
\gamma_{x y}-\alpha_{x y} \Delta T
\end{array}\right]_{k}
$$

The layer stresses are integrated through the thickness, the force resultants are,

$\left[\begin{array}{c}N_{x} \\ N_{y} \\ N_{x y}\end{array}\right]=\left[\begin{array}{lll}A_{11} & A_{12} & A_{16} \\ A_{12} & A_{22} & A_{26} \\ A_{16} & A_{26} & A_{66}\end{array}\right]\left[\begin{array}{c}\varepsilon_{x}^{o} \\ \varepsilon_{y}^{o} \\ \gamma_{x y}^{o}\end{array}\right]+\left[\begin{array}{lll}B_{11} & B_{12} & B_{16} \\ B_{12} & B_{22} & B_{26} \\ B_{16} & B_{26} & B_{66}\end{array}\right]\left[\begin{array}{c}K_{x} \\ K_{y} \\ K_{x y}\end{array}\right]-\left[\begin{array}{c}N_{x}^{T} \\ N_{y}^{T} \\ N_{x y}^{T}\end{array}\right]$

In which the $\mathrm{A}_{\mathrm{ij}}$ and $\mathrm{B}_{\mathrm{ij}}$ are the usual extensional and bending-extension coupling stiffness and the thermal forces are

$$
\left[\begin{array}{c}
N_{x}^{T} \\
N_{y}^{T} \\
N_{x y}^{T}
\end{array}\right]=\int\left[\begin{array}{lll}
\bar{Q}_{11} & \bar{Q}_{12} & \bar{Q}_{16} \\
\bar{Q}_{12} & \bar{Q}_{22} & \bar{Q}_{26} \\
\bar{Q}_{16} & \bar{Q}_{26} & \bar{Q}_{66}
\end{array}\right]_{k}\left[\begin{array}{c}
\alpha_{x} \\
\alpha_{y} \\
\alpha_{x y}
\end{array}\right]_{k} \Delta T d z
$$

In a similar manner, the moment resultants are obtained by integrating the moment of the stresses through the thickness: 
$\left[\begin{array}{l}M_{x} \\ M_{y} \\ M_{x y}\end{array}\right]=\left[\begin{array}{lll}B_{11} & B_{12} & B_{16} \\ B_{12} & B_{22} & B_{26} \\ B_{16} & B_{26} & B_{66}\end{array}\right]\left[\begin{array}{c}\varepsilon_{x}^{o} \\ \varepsilon_{y}^{o} \\ \gamma_{x y}^{o}\end{array}\right]+\left[\begin{array}{ccc}D_{11} & D_{12} & D_{16} \\ D_{12} & D_{22} & D_{26} \\ D_{16} & D_{26} & D_{66}\end{array}\right]\left[\begin{array}{c}K_{x} \\ K_{y} \\ K_{x y}\end{array}\right]-\left[\begin{array}{c}M_{x}^{T} \\ M_{y}^{T} \\ M_{x y}^{T}\end{array}\right]$

in which $\mathrm{D}_{\mathrm{ij}}$ are the usual bending stiffness and the thermal moments are,

$$
\left[\begin{array}{c}
M_{x}^{T} \\
M_{y}^{T} \\
M_{x y}^{T}
\end{array}\right]=\int\left[\begin{array}{lll}
\bar{Q}_{11} & \bar{Q}_{12} & \bar{Q}_{16} \\
\bar{Q}_{12} & \bar{Q}_{22} & \bar{Q}_{26} \\
\bar{Q}_{16} & \bar{Q}_{26} & \bar{Q}_{66}
\end{array}\right]_{k}\left[\begin{array}{c}
\alpha_{x} \\
\alpha_{y} \\
\alpha_{x y}
\end{array}\right]_{k} \Delta T . z . d z
$$

Actually, only in the restricted case of perfect constraint are $\mathrm{N}^{\mathrm{T}}$ and $\mathrm{M}^{\mathrm{T}} \cdot \mathrm{N}^{\mathrm{T}}$ and $\mathrm{M}^{\mathrm{T}}$ are thermal forces and thermal moments, respectively. However, the force and moment resultants can be rearranged to read,

$$
\begin{aligned}
& {\left[\begin{array}{l}
\bar{N}_{x} \\
\bar{N}_{y} \\
\bar{N}_{x y}
\end{array}\right]=\left[\begin{array}{l}
N_{x}+N_{x}^{T} \\
N_{y}+N_{y}^{T} \\
N_{x y}+N_{x y}^{T}
\end{array}\right]=\left[\begin{array}{lll}
A_{11} & A_{12} & A_{16} \\
A_{12} & A_{22} & A_{26} \\
A_{16} & A_{26} & A_{66}
\end{array}\right]\left[\begin{array}{l}
\varepsilon_{x}^{o} \\
\varepsilon_{y}^{o} \\
\gamma_{x y}^{o}
\end{array}\right]+\left[\begin{array}{lll}
B_{11} & B_{12} & B_{16} \\
B_{12} & B_{22} & B_{26} \\
B_{16} & B_{26} & B_{66}
\end{array}\right]\left[\begin{array}{l}
K_{x} \\
K_{y} \\
K_{x y}
\end{array}\right]} \\
& {\left[\begin{array}{l}
\bar{M}_{x} \\
\bar{M}_{y} \\
\bar{M}_{x y}
\end{array}\right]=\left[\begin{array}{l}
M_{x}+M_{x}^{T} \\
M_{y}+M_{y}^{T} \\
M_{x y}+M_{x y}^{T}
\end{array}\right]=\left[\begin{array}{lll}
B_{11} & B_{12} & B_{16} \\
B_{12} & B_{22} & B_{26} \\
B_{16} & B_{26} & B_{66}
\end{array}\right]\left[\begin{array}{l}
\varepsilon_{x}^{o} \\
\varepsilon_{y}^{o} \\
\gamma_{x y}^{o}
\end{array}\right]+\left[\begin{array}{lll}
D_{11} & D_{12} & D_{16} \\
D_{12} & D_{22} & D_{26} \\
D_{16} & D_{26} & D_{66}
\end{array}\right]\left[\begin{array}{l}
K_{x} \\
K_{y} \\
K_{x y}
\end{array}\right]}
\end{aligned}
$$

In the form of equations (9) and (10), the thermal portion of thermal and mechanical stress problems can be treated as equivalent mechanical loads defined by $\mathrm{N}^{\mathrm{T}}$ and $\mathrm{M}^{\mathrm{T}}$ in equations (6) and (8), respectively in addition to the mechanical loads, $\mathrm{N}$ and $\mathrm{M}$ [11].

\section{RESULTS AND DISCUSSION}

The thermal stress distributions are changed throughout the thickness of laminated plate, although stress distributions are obtained as same both top and bottom surfaces of the composite plate because of the symmetric orientation. Furthermore, the maximum value of thermal stress components are considered during the creation of figures, since the maximum value of thermal stresses may caused to begin a damage zone on the composite plate. The maximum values of thermal normal and shear stress components are shown as tensile form in Figure 4, whereas the compressive form of it is illustrated in Figure 5. Additionally, in these figures a, b and c are plotted for Model 1, while d, e and $f$ are drawn for Model 2. 


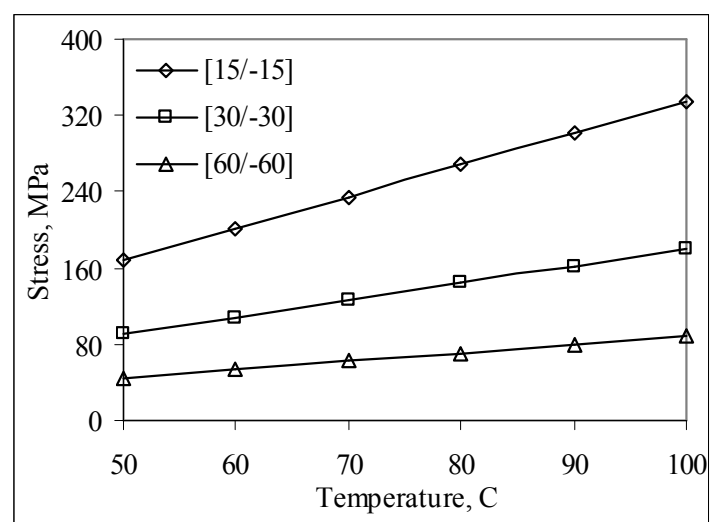

a) $\sigma_{\mathrm{x}}$ for Model 1

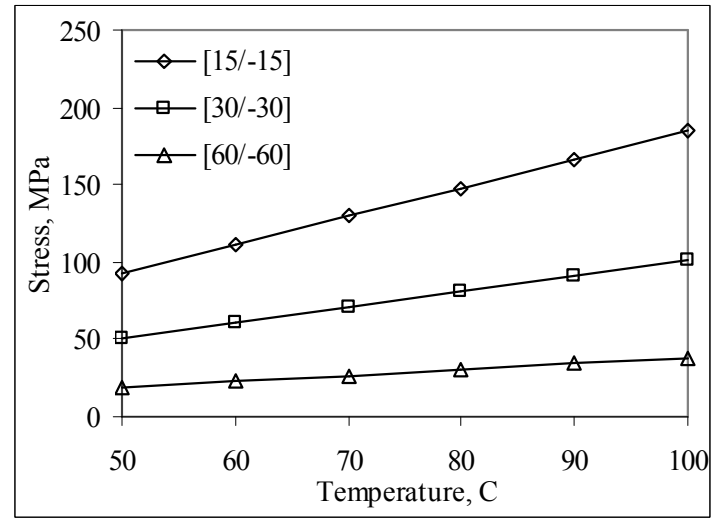

b) $\sigma_{\mathrm{y}}$ for Model 1

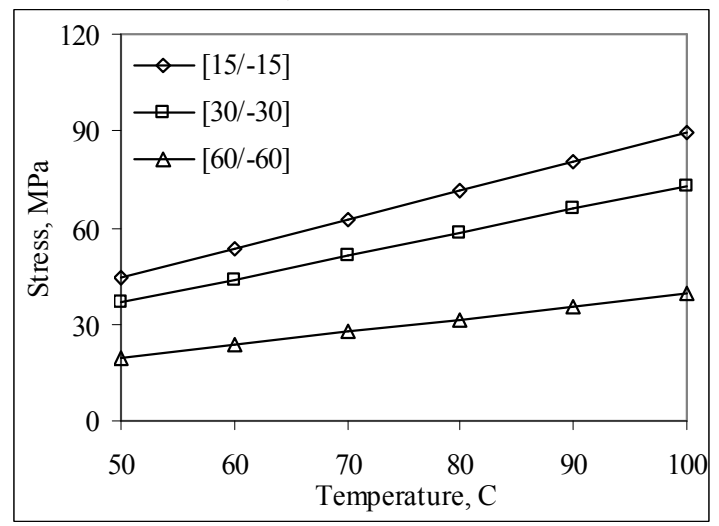

c) $\tau_{\mathrm{xy}}$ for Model 1

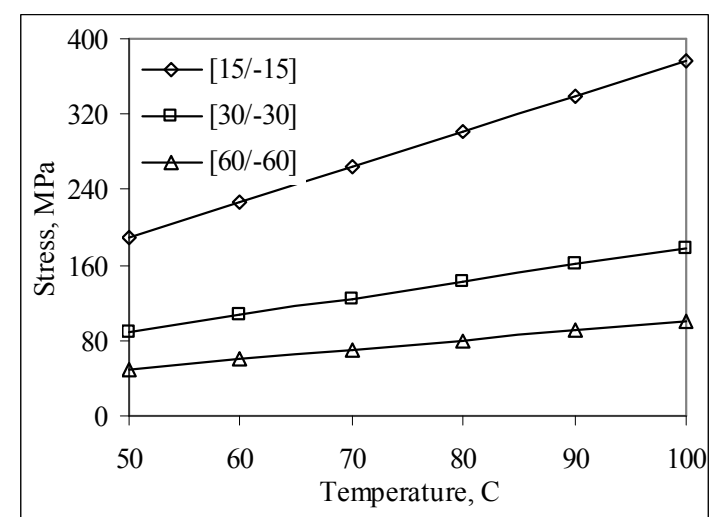

d) $\sigma_{x}$ for Model 2

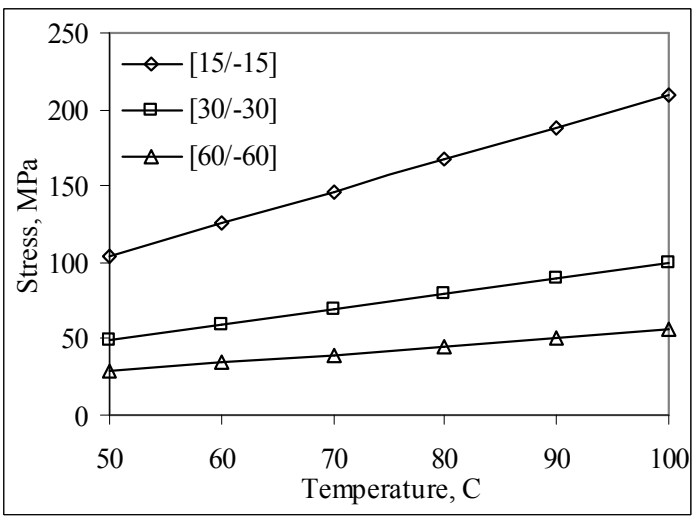

e) $\sigma_{y}$ for Model 2

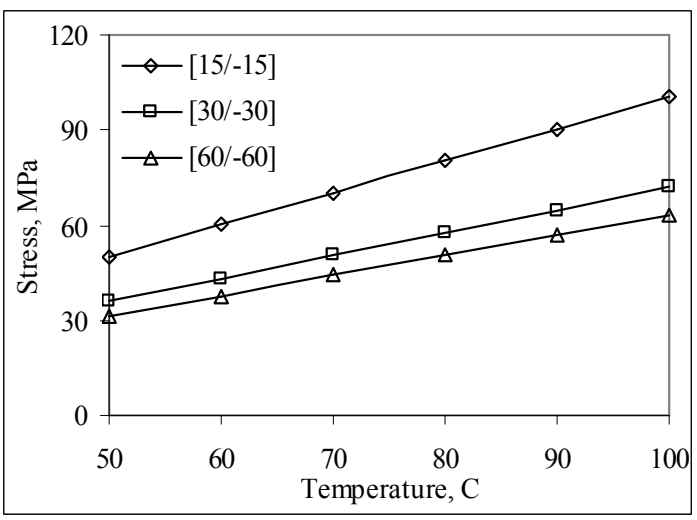

f) $\tau_{x y}$ for Model 2

Figure 4. The maximum thermal normal and shear stress components as tensile

It is seen that firstly in these figures, the absolute values of normal and shear thermal stresses are calculated for Model 2 higher than Model 1, generally. Other important point in these figures, the magnitude of thermal stresses is increasing depending on to increase of uniform temperature values. Therefore, the maximum absolute values of thermal stresses are occurred at $100{ }^{\circ} \mathrm{C}$ uniform temperature loadings, while minimum absolute values of it are obtained at $50{ }^{\circ} \mathrm{C}$ uniform temperature loadings. This case is also true for all selected lamina orientations. 


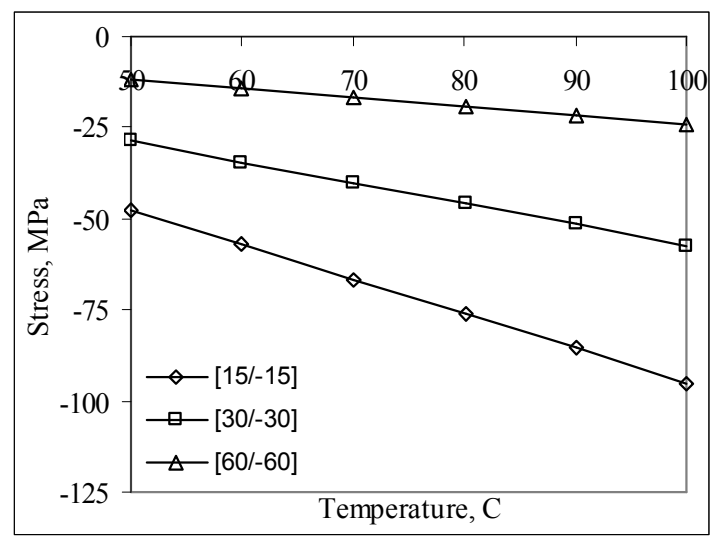

a) $\sigma_{\mathrm{x}}$ for Model 1

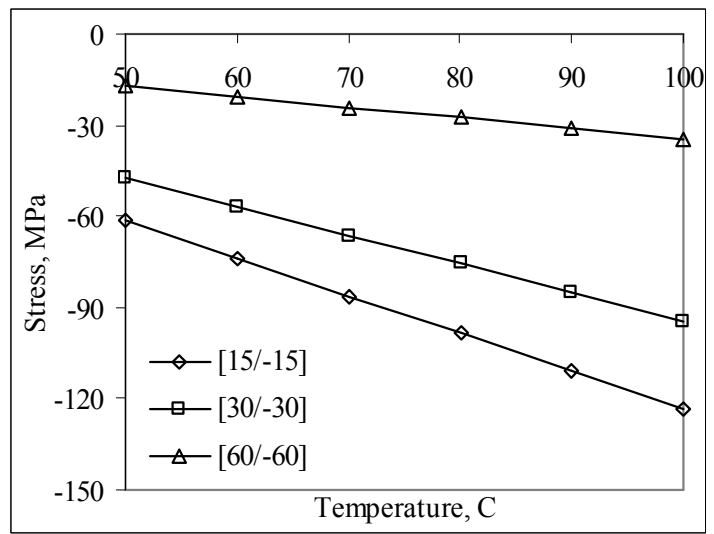

b) $\sigma_{y}$ for Model 1

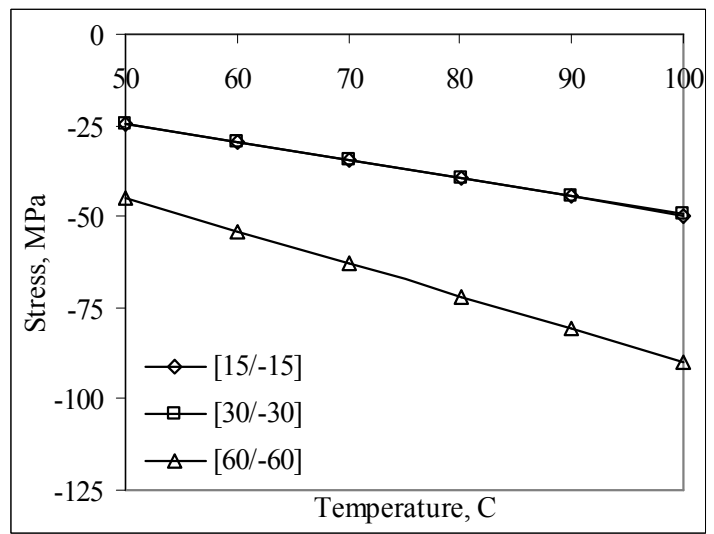

c) $\tau_{\mathrm{xy}}$ for Model 1

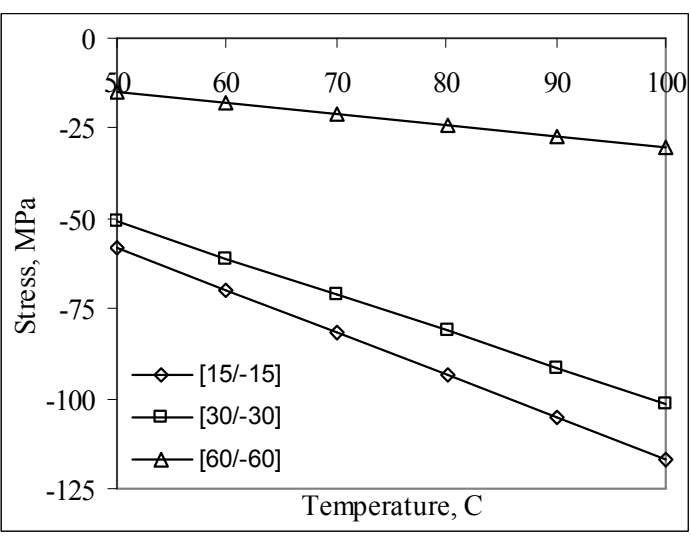

d) $\sigma_{\mathrm{x}}$ for Model 2

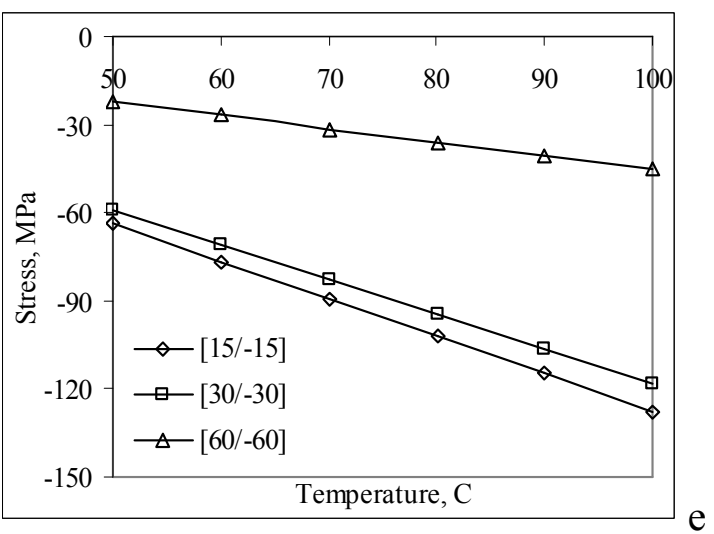

) $\sigma_{\mathrm{y}}$ for Model 2

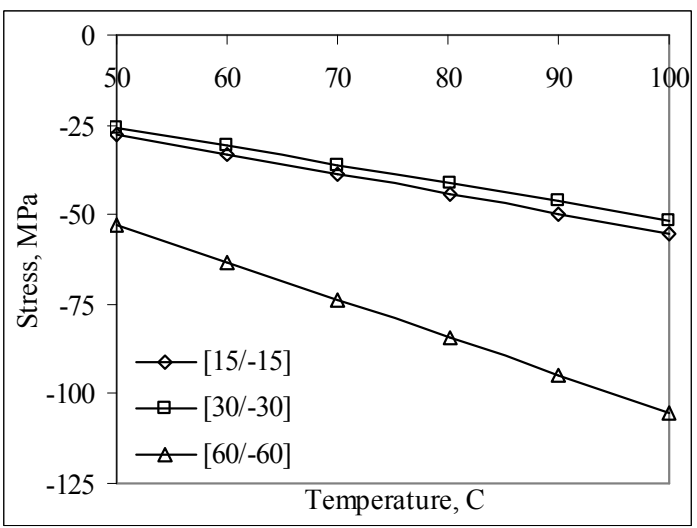

f) $\tau_{\mathrm{xy}}$ for Model 2

Figure 5. The maximum thermal normal and shear stress components as compressive

Another important point in these figures, the maximum absolute value of thermal stresses are computed for $\left[15^{\circ} /-15^{\circ}\right]_{\mathrm{s}}$ orientation, although the minimum absolute value of it are calculated for $\left[60^{\circ} /-60^{\circ}\right]_{\mathrm{s}}$ orientation. So, it can be said clearly that thermal stresses are increased, when orientation angle is decreased. Nevertheless, this case isn't true for shear stress components as compressive form, since the maximum absolute values of compressive shear stresses are obtained for $\left[60^{\circ} /-60^{\circ}\right]_{\mathrm{s}}$ orientation both Model 1 and 2. 


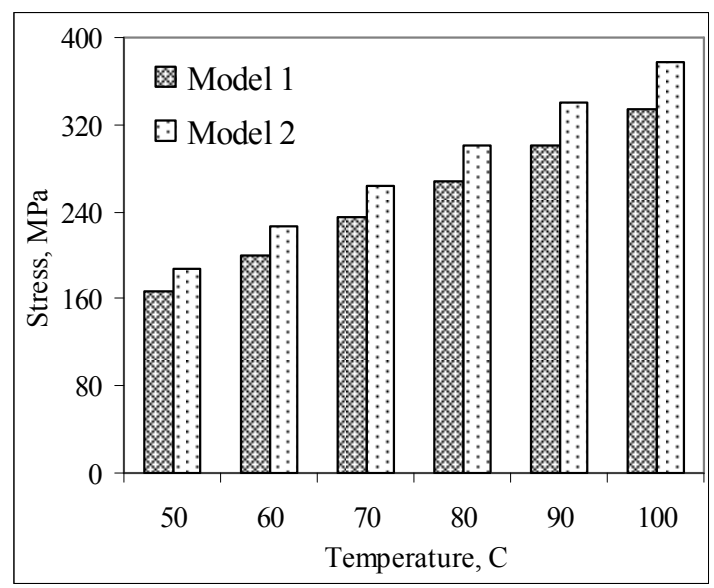

a) $\sigma_{\mathrm{x}}$ for $\left[15^{\mathrm{o}} /-15^{\mathrm{o}}\right]_{\mathrm{s}}$ orientation

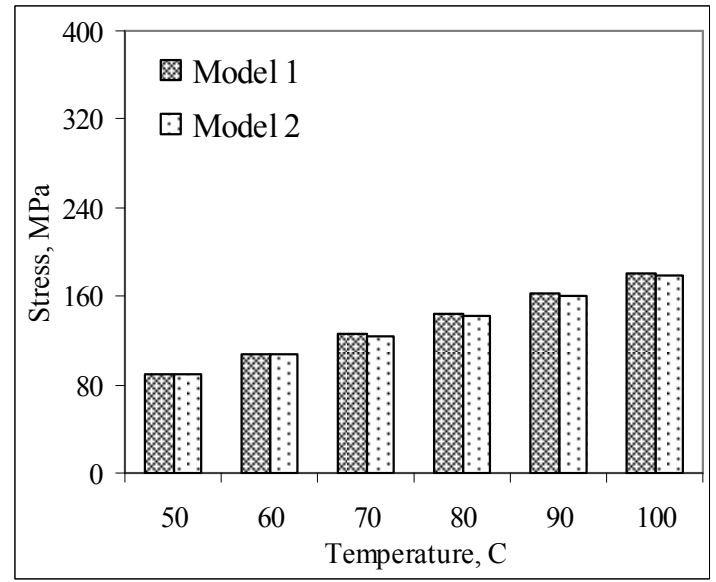

b) $\sigma_{\mathrm{x}}$ for $\left[30^{\circ} /-30^{\circ}\right]_{\mathrm{s}}$ orientation

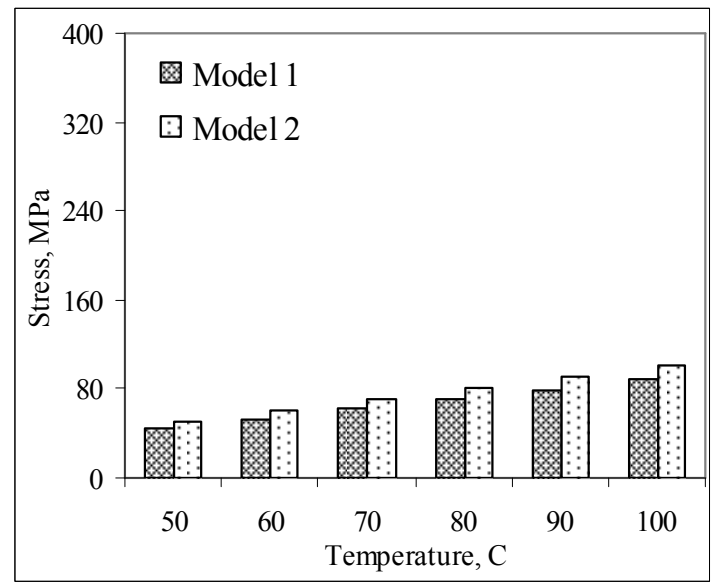

c) $\sigma_{\mathrm{x}}$ for $\left[60^{\circ} /-60^{\circ}\right]_{\mathrm{s}}$ orientation

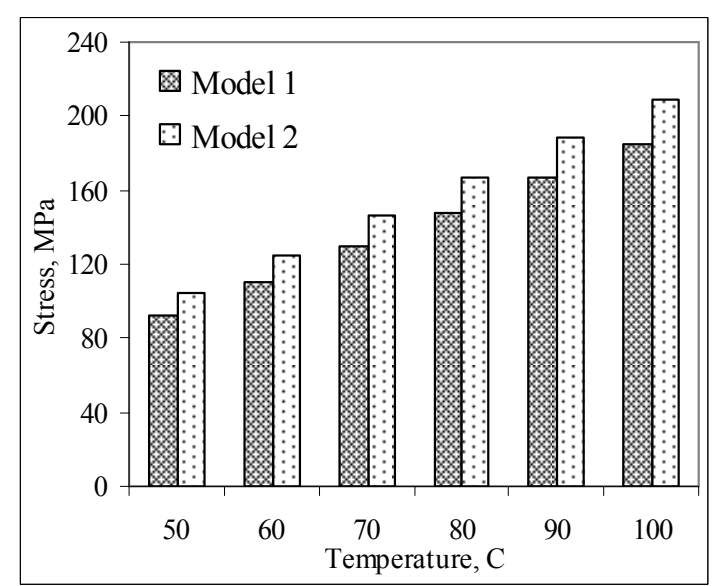

d) $\sigma_{\mathrm{y}}\left[15^{\mathrm{o}} /-15^{\mathrm{o}}\right]_{\mathrm{s}}$ orientation

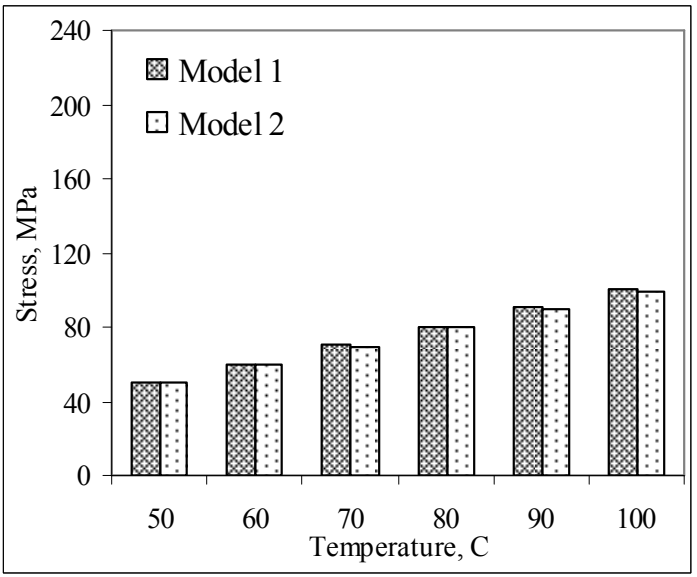

e) $\sigma_{\mathrm{y}}\left[30^{\circ} /-30^{\circ}\right]_{\mathrm{s}}$ orientation

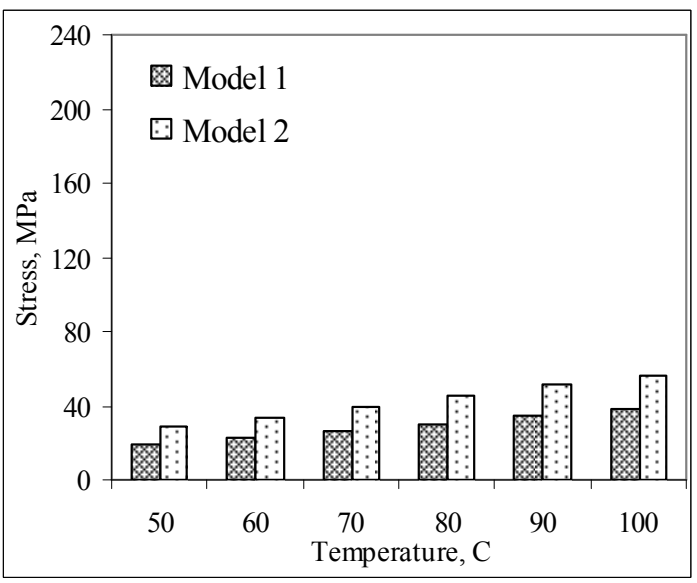

f) $\sigma_{\mathrm{y}}\left[60^{\circ} /-60^{\circ}\right]_{\mathrm{s}}$ orientation

Figure 6. A comparison of the maximum normal stress components between Model 1 and Model 2 as tensile

A comparison of the maximum normal stress components between Model 1 and Model 2 as tensile form is shown in Figure 6. In this Figure, $\mathrm{a}, \mathrm{b}$ and $\mathrm{c}$ are created for $\mathrm{x}$ direction, 
while $\mathrm{d}$, e and f are plotted y-direction depending on selected orientations. It is seen that in this figure, thermal stresses are obtained for Model 2 very upper than Model 1 both $\left[15^{\circ} /-15^{\circ}\right]_{\mathrm{s}}$ and $\left[60^{\circ} /-60^{\circ}\right]_{\mathrm{s}}$ orientations, nonetheless thermal stresses are computed for Model 1 higher than Model 2 for $\left[30^{\circ} /-30^{\circ}\right]_{\mathrm{S}}$ orientation. However, the difference is very small and thermal stresses nearly equal each other for $\left[30^{\circ} /-30^{\circ}\right]_{\mathrm{s}}$ orientation, so the difference is negligible for this orientation. Furthermore, thermal stresses are estimated for $\left[60^{\circ} /-60^{\circ}\right]_{\mathrm{s}}$ orientation very smaller than other orientations both $\mathrm{x}$ and $\mathrm{y}$-directions at same uniform temperature loadings.

In Figure 7, a comparison of the maximum shear stress components as tensile form between Model 1 and Model 2 are presented depending on applied uniform temperature loads. The distributions of thermal shear stress components are obtained as similar of normal stress components in Figure 6. Therefore, same results, which are mentioned above for Figure 6, are said for comparison of maximum shear stress components in Figure 7.

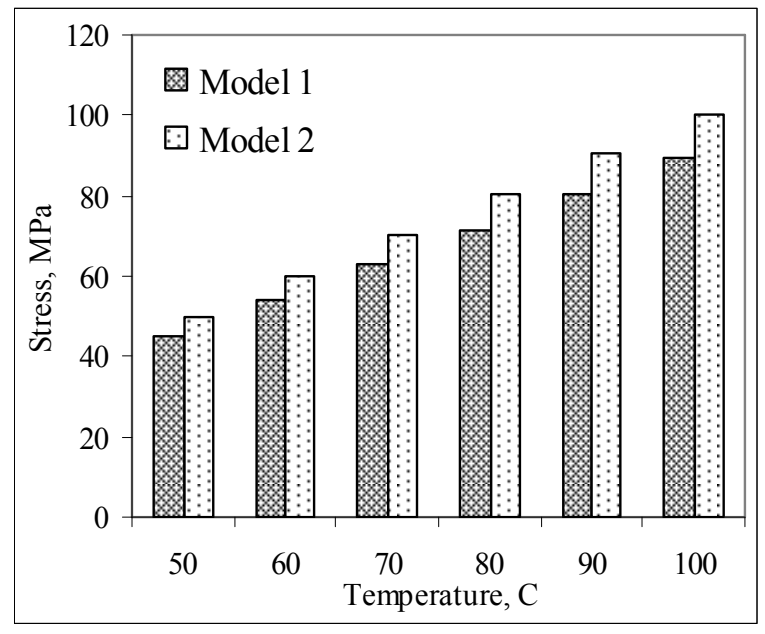

a) $\tau_{\mathrm{xy}}$ for $\left[15^{\circ} /-15^{\circ}\right]_{\mathrm{s}}$ orientation

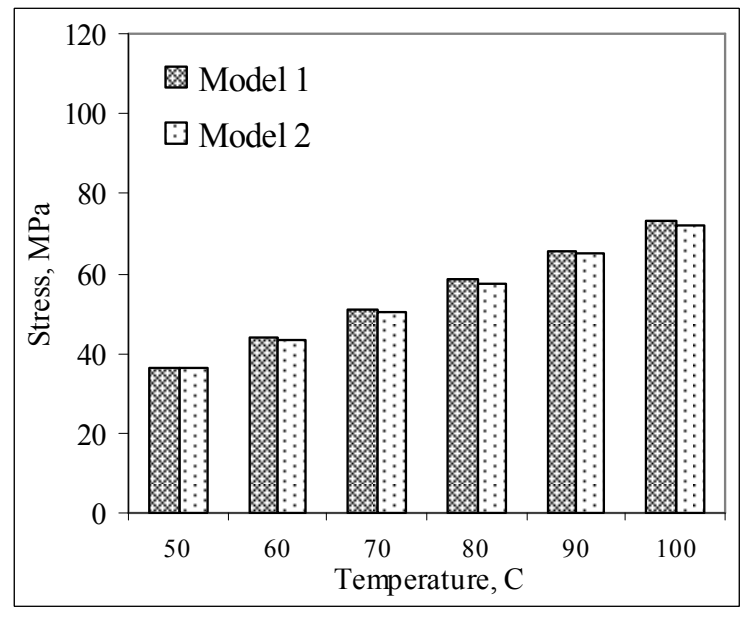

b) $\tau_{\mathrm{xy}}$ for $\left[30^{\circ} /-30^{\circ}\right]_{\mathrm{s}}$ orientation

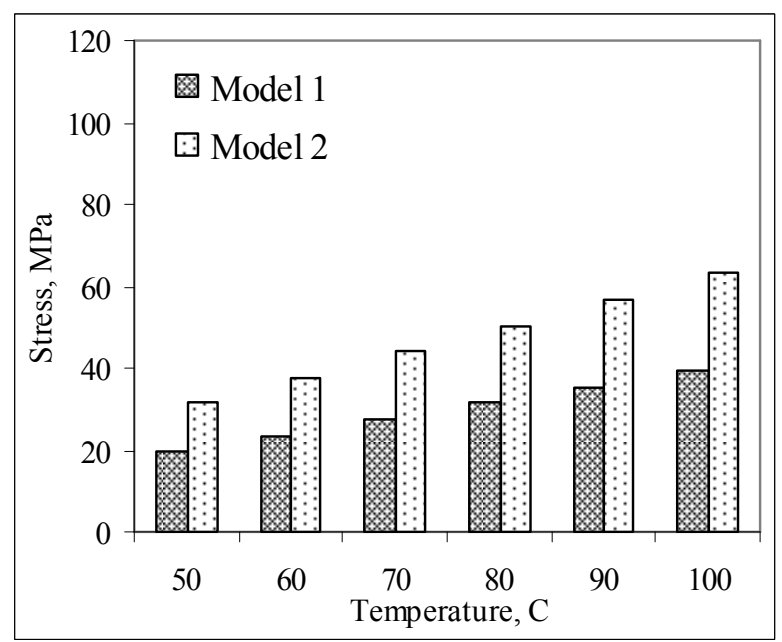

c) $\tau_{\mathrm{xy}}$ for $\left[60^{\circ} /-60^{\circ}\right]_{\mathrm{s}}$ orientation

Figure 7. A comparison of the maximum shear stress components between Model 1 and Model 2 as tensile 
According the results of this study, it is said clearly that thermal stress components for laminated thermoplastic square composite plates with a square hole are strictly effected stacking sequence of laminates and the size of square hole.

\section{CONCLUSIONS}

The following results are concluded from this study;

1. The magnitude of the thermal stresses increase related to get higher of uniform temperature values, therefore the highest values of it are obtained at $100{ }^{\circ} \mathrm{C}$ uniform temperature applications.

2. The values of thermal stresses are effected stacking sequence of the laminated plates.

3. The distributions of thermal stresses are changed because of the different $\mathrm{a} / \mathrm{b}$ ratio of square laminated composite plate with square hole.

4. The magnitude of the thermal stress components at the upper and lower layers of symmetric laminated plates are the same.

\section{REFERENCES}

1. Y. M. Haddad, Advanced multilayered and fibre-reinforced composites, Kluwer Academic Publishers, Netherlands, 1998.

2. C. H. Wang, , L. R. F.Rose, R. Callinan, A.A. Baker, Thermal stresses in a plate with a circular reinforcement, Int. Journal of Solids and Structures, 37: 4577-4599, 2000.

3. M. Gigliotti, F. Jacquemin, and A. Vautrin, On the maximum curvatures of 0/90 plates under thermal stres, Composite Structures, 68, 177-184, 2005.

4. O. Sayman and M. Kayrici, An elastic-plastic stress analysis in a thermoplastic composite cantilever beam, Composite Science and Technology, 60, 623-632, 1999.

5. M. Şenel, H. Akbulut and M. Toparl1, Residual stress analysis in symmetric thermoplastic laminated plates under thermal loads analytic solution, Journal of Thermoplastic Composite Materials, 17, 481-507, 2004.

6. Y. M. Shabana, and N. Noda, Thermo-elasto-plastic stresses in functionally graded materials subjected to thermal loading taking residual stresses of the fabrication process into consideration. Composites Part B: Engineering, 32: 111-121, 2001.

7. O. Sayman, R. Karakuzu, B. Daghan, and S. Kocak, Elastic-plastic stress analysis of thermoplastic composite beams under temperature distributed linearly, Journal of Thermoplastic Composite Materials, 15, 193-208, 2002.

8. A. Ondurucu, and M. Topcu, Thermal residual stresses in simply supported thermoplastic laminated plates under a parabolic temperature distribution, Journal of Thermoplastic Composite Materials, 19, 155-171, 2006.

9. F. Şen, An investigation of thermal elasto-plastic stress analysis of laminated thermoplastic composites with a circular hole under uniform temperature loading, Science and Engineering of Composite Materials, 13, 213-225, 2006.

10. ANSYS 8.0, The general-purpose finite element software, Documentation.

11. R.M. Jones, Mechanics of composite materials, Taylor \& Francis Inc., USA, 1999. 